\title{
The Significance of Jacob Bernoulli's Ars Conjectandi for the Philosophy of Probability Today
}

\author{
Glenn Shafer \\ Rutgers University
}

\begin{abstract}
More than 300 years ago, in a fertile period from 1684 to 1689, Jacob Bernoulli worked out a strategy for applying the mathematics of games of chance to the domain of probability. That strategy came into public view in August 1705, eight years after Jacob's death at the age of 50, when his masterpiece, Ars Conjectandi., was published.

Unfortunately, the message of Ars Conjectandi was not fully absorbed at the time of its publication, and it has been obscured by various intellectual fashions during the past 300 years.
\end{abstract}

The theme of this article is that Jacob's contributions to the philosophy of probability are still fresh in many ways. After 300 years, we still have something to learn from his way of seeing the problems and from his approach to solving them. And the fog that obscured his ideas is clearing. Our intellectual situation today may permit us a deeper appreciation of Jacob's message than any of our predecessors were able to achieve.

I will pursue this theme chronologically. First, I will review Jacob's problem situation and how he dealt with it. Second I will look at the changing obstacles to the reception of his message over the last three centuries. Finally, I will make a case for paying more attention today. 


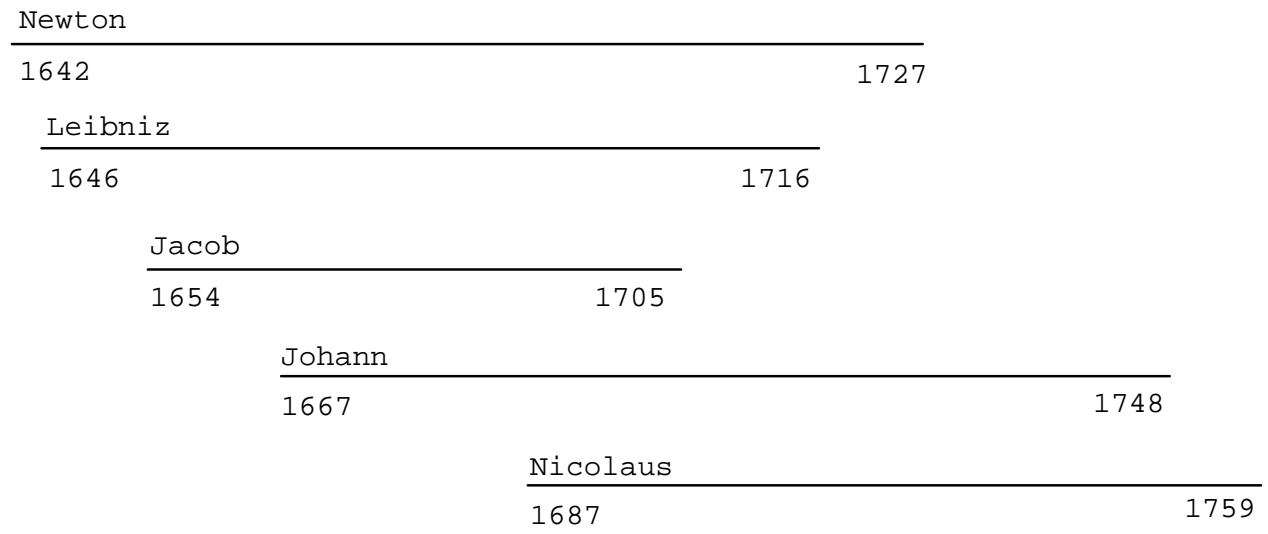

Figure 1 Jacob's contemporaries.

\section{Jacob's Problem Situation}

Jacob Bernoulli was born in Basel on the 27th of December of 1654, the same year probability was born in Paris. When I say probability was born in Paris, I am thinking, of course, of Blaise Pascal's solution of the problem of points: if Peter and Paul are contending on equal terms, Peter lacks two points, Paul lacks one, and they end the game, how should they share the stakes? Pascal was the first to answer this question correctly, and Pierre Fermat, his Toulouse correspondent, was the second. Christiaan Huygens, who heard of their work, rediscovered their reasoning, and wrote it up in the widely circulated De ratiociniis in ludo aleae, might be counted as the third.

Pascal, Fermat, and Huygens were concerned with a problem of equity, not a problem of probability. They were pricing gambles, not evaluating evidence or argument. But it did not take people long to draw the analogy. In 1662, the year Pascal died and Jacob turned eight, Pascal's friends at Port Royal published their famous logic text, which leaned heavily on the gambling analogy when it turned to probability. In a passage that strikingly anticipates later developments, the Port Royal Logic uses the word "probability" quantitatively. We should, the authors say, apportion our hopes and fears to the probabilities of the events we hope for and fear. 
When Jacob began his work on probability, at the age of 30 in 1684, not much more had happened, and what little had happened Jacob knew little about. Huygens's tract was the only book on equity in games of chance that Jacob had. He did not have Pascal's Traité du triangle arithmétique or Jan de Witt's Waerdye van Lyf-Renten.

A little more detail may help us adjust our thinking to an age of slower communication. Pascal's treatise on the arithmetic triangle was published in Paris in 1665, three years after Pascal's own death. Jacob was ten years old. De Witt's report on the pricing of annuities was presented to the States-General of Holland and West Friesland in 1671. Jacob was sixteen. In retrospect, these two little books are milestones in the history of probability. But Jacob Bernoulli, famed throughout Europe for his contributions to the calculus of variations, the Professor of Mathematics at the University of Basel, a mere 400 miles from Paris and now a leisurely five-day cruise from Amsterdam, apparently never laid his hands on either book. It is clear from Jacob's treatment of the combinatorics of the binomial that he never saw Pascal's treatise. He did know about de Witt's work because it had been reviewed in Leibniz's Acta Eruditorum, but he was never able to find a copy. He repeatedly asked Leibniz's help in finding the book, and in April of 1705, a few months before Jacob died, Leibniz wrote to apologize for the third time for not being able to find and send Jacob his copy. It was not a great loss, Leibniz insisted, for de Witt had not gone beyond the principles used by Pascal in his Traité du triangle arithmétique and by Huygens in his De ratiociniis in ludo aleae. This may have been the first time Jacob had heard of Pascal's treatise.

Publishing obviously had a different meaning at the end of the seventeenth century than at the end of the twentieth. It meant you had some copies printed and sold them. We know that Pascal wrote his treatise and had it printed at the time of his correspondence with Fermat. But when he repented of mathematics and turned back to God, the copies were put in a closet. The printer put a new front page on them and sold them in 1665. A half-hearted publication. But apparently Leibniz had a copy. So did 
Montmort, the French nobleman who could afford to have many copies of his own Jeux de Hazard printed in 1708, and who first attached Pascal's name to the age-old combinatorial triangle.

So Jacob saw much to do when he went to work on Huygens's theory in 1684 . He undertook to do it all in Ars Conjectandi. In Part I, he explained Huygens's tract and solved the problems Huygens had given at the end. In Part II, he studied combinatorics. In Part III, he took on many of the popular card and dice games of the day. And in Part IV, he showed how the theory of equity could be applied to the domain of probabilityhow it could be applied to civilibus, moralibus, \& oeconomicis - to the political, judicial, personal, and business decisions for which arguments and evidence must be weighed.

My topic, of course, is Part IV: Jacob's struggle to apply Huygens's work to probability. I will argue that Jacob's struggle was similar to our own struggle to understand the scope of application of probability, and that the very difference between Jacob's problem situation and ours can make his approach fresh and informative for us. The difference is that Jacob could not take numerical probability for granted. In 1684, a probability was an argument, not a number between zero and one. There was no presumption that events or propositions or things ("thing" is the word Jacob usually used: res in Latin) had numerical probabilities. It was presumed instead that they have arguments pro and con. Jacob had to make the case for the existence and meaningfulness of numerical probabilities. And he had to reconcile that case with existing presumptions about what probability meant and how it worked. 

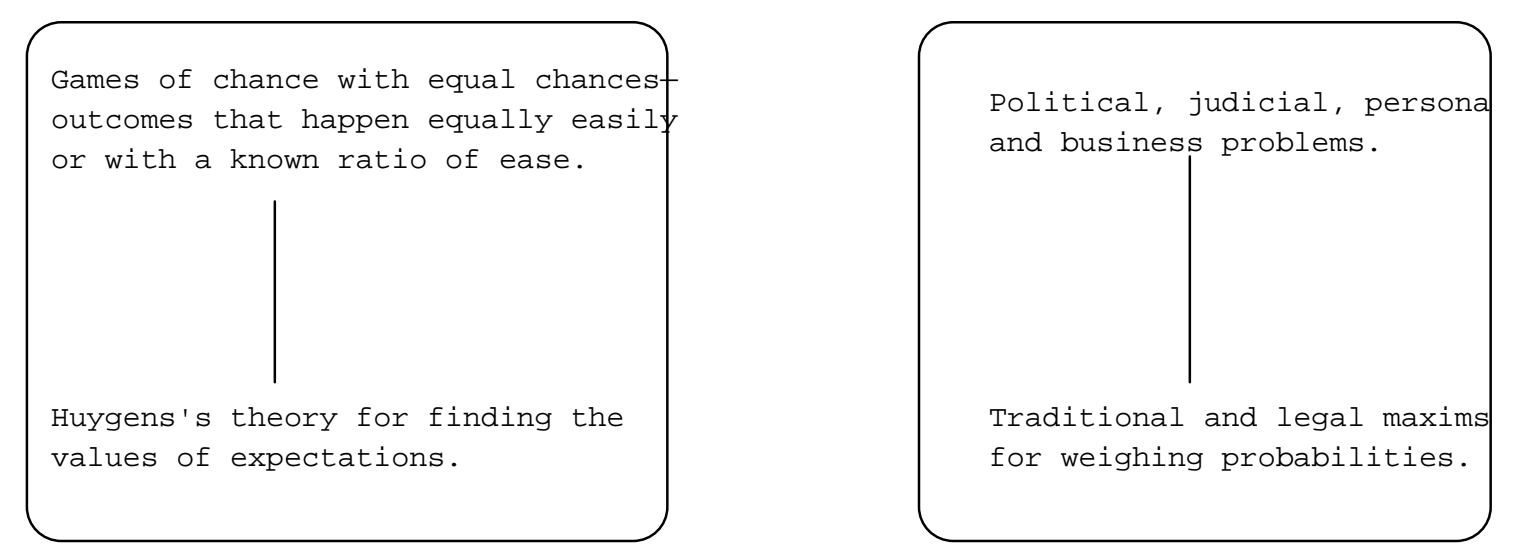

Figure 2 The gap between probability and Huygens's theory of equity.

Here is the crux of the matter. Before Jacob set to work, the word "probability" did not belong to the mathematical theory it now names. Probability belonged to the world of practical problems and arguments. The mathematical theory was a theory of equity. Figure 2 shows the situation with which Jacob had to deal. Games of chance on the one side, and probability on the other. Probability is on the side with the problems. Jacob's task was not to apply probability. It was to apply the theory of equity in games of chance to probability.

One symptom of this situation is that the word "probability" was not used in Huygens's theory. No one thought to call the proportion of the stakes due a particular player his "probability" of winning. This would have sounded odd, because probability was not a number, and because when you were talking probability, you were supposed to talk about all the probabilities_-all the arguments pro and con.

Another symptom was that people continued to talk about probability without any thought of Huygens's mathematical theory. This includes Huygens himself. Barbara Shapiro, in her book on the very considerable role of non-numerical probability in English thought in the seventeenth century, sees Huygens as typical in his insistence that knowledge in science is only probable but may be very probable. In his Treatise on Light, Huygens writes that it is possible 
to attain ... a degree of probability which very often is scarcely less than complete proof. To wit, when things have been demonstrated by the Principles that have been assumed to correspond perfectly to the phenomena which experiment has brought under observation: especially when there is a great number of them, and further, principally, when one can imagine and foresee new phenomena, which ought to follow from the hypothesis which one employs, and when one finds that therein the fact corresponds to our prevision. But if all these proofs of probability are met with in that which I propose to discuss, as it seems to me they are, this ought to be a very strong confirmation of the success of any inquiry.

Here Huygens is drawing on the received wisdom of his time, without a thought to the little tract about games of chance he wrote some years before.

Some people had thought of making probability numerical. As Lorraine Daston has pointed out, the legal tradition in Europe in the seventeenth century had an extensively developed arithmetic of proof, in which different kinds of evidence were assigned different weights. The arithmetic involved scarcely resembled, however, Huygens's arithmetic of price. As Ian Hacking has pointed out, Leibniz's baccalaureate essay of 1665, De conditionibus, was written in this legal tradition; it proposed attaching numerical degrees of proof or probability, scaled between zero and one, to conditional rights, but it drew no connection with Huygens's theory, which Leibniz presumably did not know about at the time.

As I have already mentioned, once Pascal's and Huygens's work became known, people did think about trying to use it in the larger realm of probability. Pascal himself used the ideas in his famous wager for the existence of God. And the Port Royal Logic speaks of degrees of probability. But these were isolated projects. There remained a tremendous conceptual gap between Huygens's theory and the general realm of 
probability. No one had built a philosophically and practically convincing bridge across this gap.

What was Jacob's strategy for bridging the gap? It had three elements. First, Jacob's great theorem - the law of large numbers, as Poisson later called it—tells us that we can use experience to find the relative ease with which outcomes occur, so that we will be in as strong an epistemic position in ordinary problems as we are in games of chance, where we know that the outcomes happen equally easily. Second, Jacob's rules for the numerical combination of independent arguments express the traditional content of probability theory in philosophy, theology, and the law-maxims and rules for combining of arguments - in terms of Huygens's theory. Third — this is the philosophical glue that holds it all together_Jacob defines probability as a part of certainty: "Probabilitas enim est gradus certitudinis, \& ab hac differt ut pars à toto." ("Probability is a degree of certainty, and differs from certainty as a part from a whole.”) Arguments in practical problems earn a certain portion of certainty, just as a position in a game of chances earns a certain portion of the stake.

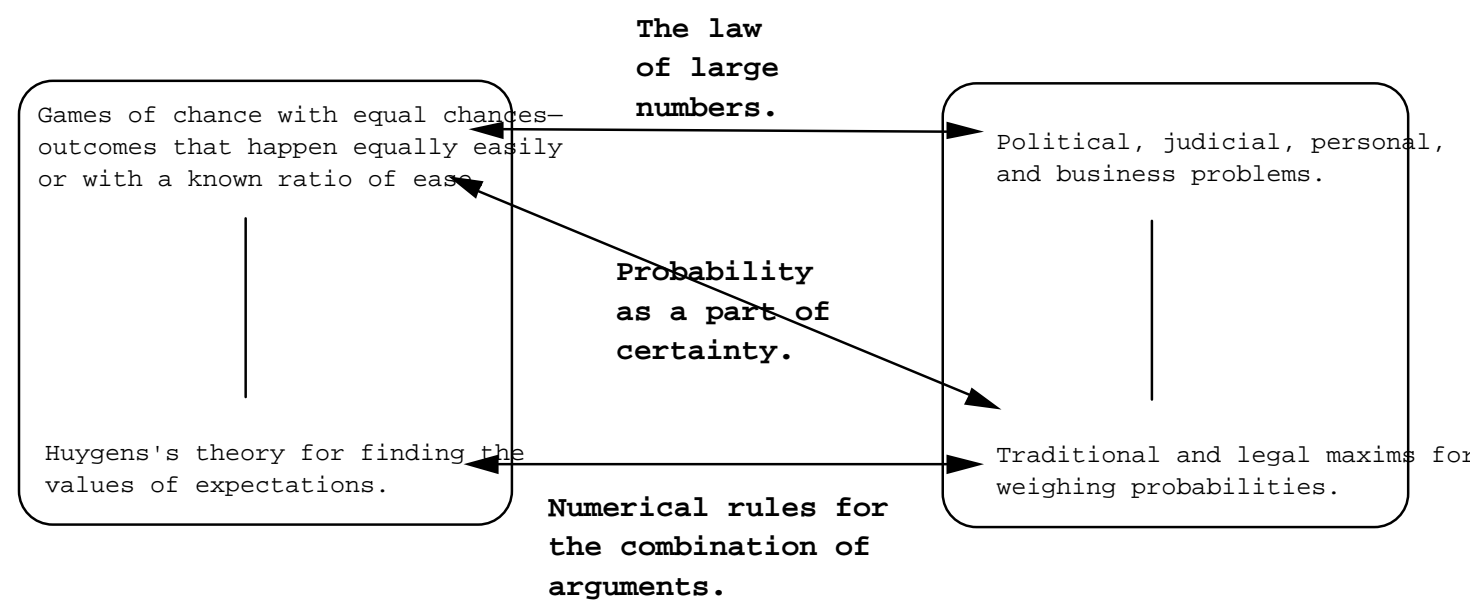

Figure 3 Jacob's three-fold strategy for bridging the gap.

Jacob was excited about his strategy; he did not underestimate the importance of what he was doing. But he was relatively relaxed and candid about the possibility of failure in 
individual problems. Both horizontal arrows in Figure 3 are points where the strategy can break down. In his correspondence with Leibniz, Jacob concedes that we will not always have the observations to estimate the ease with which different outcomes happen, and he acknowledges that we will have to deal with changing conditions. And when he gives his rules for combining arguments, he acknowledges that the result can be inconclusive. In some cases, both sides of an argument might be deemed highly probable. In other cases, arguments might be too intertwined to combine.

It is the picture that I have just drawn, and the recognition that there is a gap that needs to be bridged but might not be bridged that I would like us today to regain from Jacob.

Before moving on from Jacob's ideas to their later reception, I need to correct one omission: so far I have left the English cleric George Hooper out of the story. Hooper is the one person who anticipated, or at least independently discovered, part of Jacob's program. Hooper had no inkling of Jacob's theorem, but he did speak of probability as a number between zero and one, and in 1689 , in the course of a lengthy tract refuting the doctrine of the infallibility of the Roman Catholic pope, Hooper gave two rules for the combination of testimony, rules that can be seen as special cases of Jacob's rules for combining arguments. He repeated these rules in a brief anonymous article in the Philosophical Transactions of the Royal Society in 1699. Since we do not have evidence from Jacob's Meditationes about when Jacob first formulated his rules for combining arguments, it is not impossible that he was influenced by Hooper.

\section{The Eighteenth-Century Fate of Jacob's Program}

Jacob's imaginative program for probability did not prosper after his death. Perhaps the time was not ripe for the applications he had in mind. But we can also blame the delay in publication of Ars Conjectandi, a delay that allowed the intellectual space to be filled with subtly different projects. 
According to B.L. van der Waerden's careful study of Jacob's Meditationes, the diary in which he recorded his philosophical and mathematical work, Jacob had worked out most of his ideas on probability during the years from 1684 to 1689 , when he was 30 to 35 years old. We can only speculate about when he reworked and extended this material into Ars Conjectandi. Was he at work on the book during the 1690s, when he contributed to Leibniz's calculus and engaged in the bitter competition with his brother Johann, 13 years his junior, to develop the calculus of variations? Or did he turn back to it only in the last years of his life? We do know that he left Part IV unfinished when he died in 1705, at the age of 50. He had completed the theory, but he had yet to implement it. He hoped to find data, perhaps in de Witt's book, that would enable him to illustrate how experience could be used to weigh arguments.

Jacob's ambitious design for Ars Conjectandi had already delayed the publication of his ideas for 15 years when he died. This was followed by a further delay of eight years. In van der Waerden's 1975 volume, K. Kohli has provided a valuable account of this second delay. As Kohli explains, the delay was due to the distrust Jacob's widow and son felt towards of the other mathematicians in the family, Jacob's brother Johann and nephew Nicolaus. (Johann was 36 when Jacob died. He would live for another 43 years. Nicolaus was only 17.) Kohli traces the widow's and son's hesitations using the correspondence between the Baselers (Johann, Nicolaus, and Jacob's student Jacob Hermann, who was 27 when Jacob died) and luminaries such as Leibniz and Varignon. When Jacob died, Hermann told Paris (and thus the academic world) of the existence and the "unfinished" character of Ars Conjectandi, thus setting up a small but continuing clamor for its completion and publication. Saurin, Leibniz, and Montmort all wrote to Johann urging him to complete the book and bring it to publication: a brother's duty. Johann responded that the heirs would not let him close to the manuscript. And it was just as well; he had better things to do. 


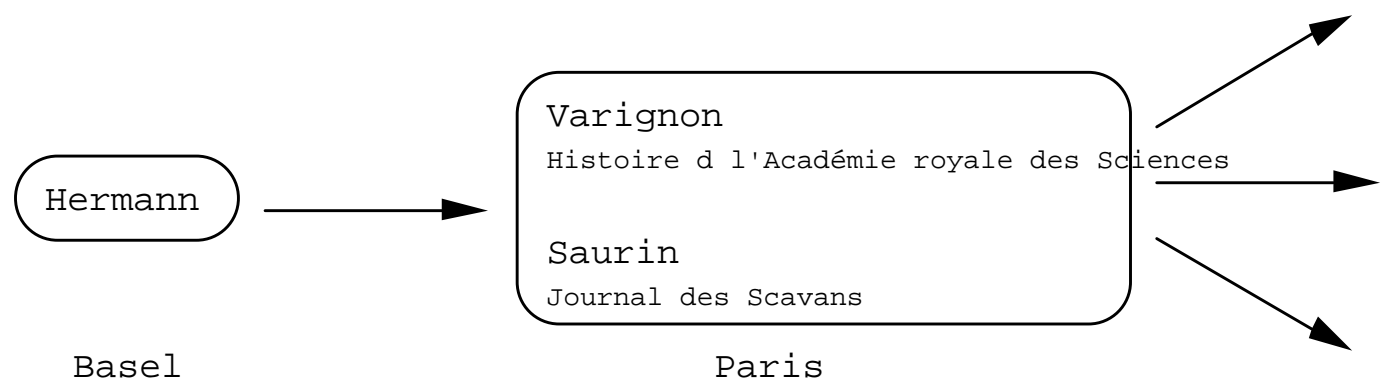

Figure 4 The dissemination of information in 1705.

Nicolaus must have studied the manuscript of Ars Conjectandi when he worked as a secretary to his uncle. In 1709 , at age of 22 , he puts its ideas to use in his own doctoral dissertation in law: de Usu Artis Conjectandi in Jure. So the widow and son had both John and Nicolaus exploiting Jacob's ideas. And there was no one else in Basel qualified to help. (Leibniz had found a job for Hermann in Padua in 1707.) The son was supposed to get Varignon's advice on the publication of his father's papers when he went to Paris to study, but the son was an artist, not a mathematician, and the next we hear he is in Venice. Finally in 1710, Montmort wrote to Johann and Nicolaus offering to pay to have Ars Conjectandi printed. The offer was never accepted, but apparently Nicolaus used it to persuade his cousin and finally his aunt to proceed with the publication; Nicolaus wrote a preface and a page of errata. The book remained as "unfinished" as it had been in 1705.

The human story has its own interest, but I also want to call your attention to its implications for the reception of Jacob's work. While his heirs hesitated, othersespecially Nicolaus, Montmort, and De Moivre-were developing their own take on numerical probability.

In 1708, Montmort, in the first edition of his Jeux de Hazard, candidly admitted that he could not see how to pursue Jacob's project, of which he had read in the obituaries. He did not see how to make the assumptions needed to apply the theory of games of chance outside its own domain. But Montmort's work on games of chance was already 
going beyond Jacob's Part III in many respects. Nicolaus was also making strides. When Nicolaus first studied Ars Conjectandi, he lacked the mathematical maturity to absorb all its ideas, but by the time he was allowed to prepare the errata, he had already proven his own version of the law of large numbers; he remembered vaguely that his uncle had proven something similar, but he was inspired not by his uncle's philosophical agenda but by Arbuthnot's puzzlement over the inequality in the numbers of boys and girls.

So by the time the great book was published it was obsolete. Kohli sums the matter up with a passage in a letter from Montmort to Nicolaus dated Christmas 1713: "Il est vray, ce que vous diste, qu'il y a peu de choses à apprendre pour nous, qui avons beaucoup pensé à ces matières. Le livre ne laisse pas d'estres excellent." At the end of 1713, the state of the art in the theory of equity in games of chance was not Ars Conjectandi. It was the second edition of Montmort's Jeux de Hazard, replete with the latest thinking on the topic by Montmort, Nicolaus, and Johann.

Though it was mathematically obsolete, Ars Conjectandi still packed a powerful wallop philosophically. It gave an elegant and convincing and justification for bridging the gap between Huygens and probability. But here is the larger tragedy. Jacob's immediate mathematical successors, Nicolaus, Montmort, and De Moivre, already well launched on extending Huygens's theory to more complex games and to the most obvious applications outside of games—annuities and insurance—-had little use for Jacob's elegant general bridge to the world of evidence and argument. They were content to take advantage of Jacob's most superficial accomplishment: the incorporation of the word "probability," with all its prestige and claim to generality, into Huygens's theory. In the place of the Jacob's picture, they had a picture more like Figure 5.

You can see my point if you look at the first edition of Abraham De Moivre's Doctrine of Chances, which appeared in 1718, five years after Ars Conjectandi. The influence of Jacob is evident in the early introduction of the word "probability," which had not appeared in De Moivre's earlier De mensura sortis. But the other elements of 
Jacob's strategy are nowhere to be seen. Jacob's theorem is scarcely mentioned (it appears in the second edition, in 1738), and there is nothing remotely like Jacob's rules for combining arguments.

De Moivre's reception of Jacob's ideas was both influential and typical. Without a doubt, Jacob had a decisive influence in bringing "probability" into the "Doctrine of Chances," but probability became anchored within that doctrine in a very different way than Jacob had intended. The number represented by the name probability began to play a role internal to the theory. The name itself, instead of forcing the theory to deal with traditional, legal, and commonsensical rules for the combination of arguments, became an excuse for the presumption that the theory could be "applied" as a substitute for those rules.

In Figure 5, in contrast with Figure 3, all the work goes on inside the mathematical theory. In Figure 3, the practical arguments appropriate to the practical problems did their traditional work, and it was the duty of the theory to come to terms with these arguments. In Figure 5, the practical problems are merely examples of the theory. 


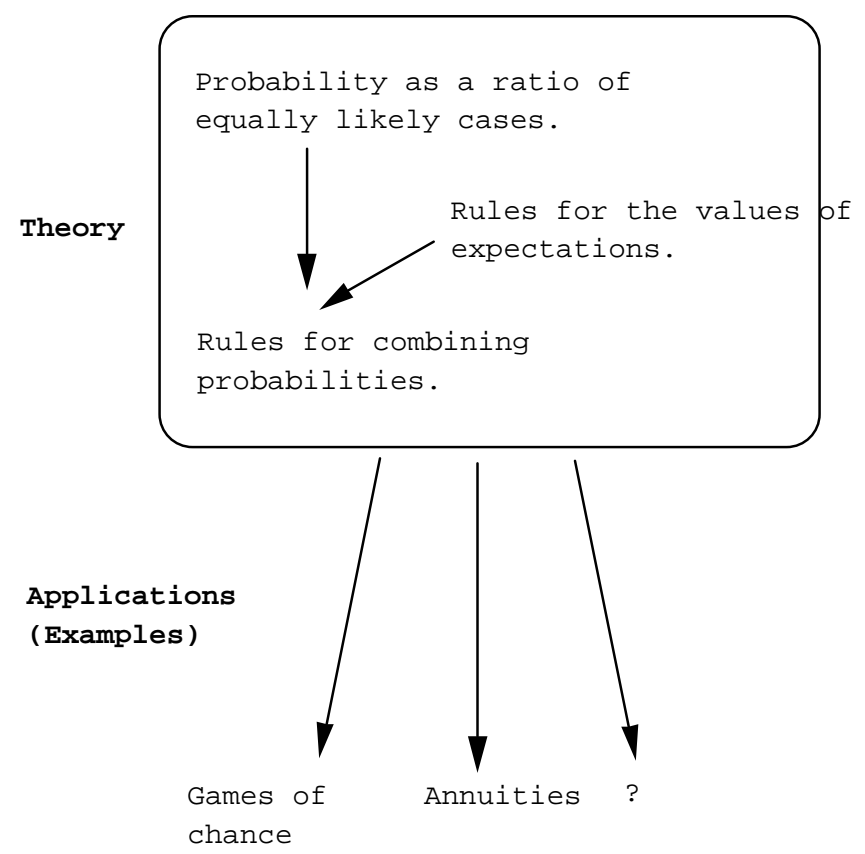

Figure 5 De Moivre's picture of probability and its applications.

Before leaving Figure 5, I should also comment on the arrows inside the box marked theory, arrows which may puzzle some readers. Today, most authorities derive rules for expected values from rules for probabilities. But for De Moivre, the arrow still went the other way. When you read closely his explanations for the rules of probability, you see that he is still using Huygens's rules for the prices of expectations as his starting point. Numerical probability was still novel enough that no one could take its rules for granted. They had be derived from Huygens's rules, which could be justified directly using the idea of fairness.

We should not exaggerate De Moivre's importance in the eighteenth century. In retrospect, he represents the path that mathematical probability followed, but he was hardly a philosopher of Jacob's caliber, and Jacob retained a strong influence throughout the century among those who wanted to understand probability philosophically. Jacob's and Hooper's rules survived the whole course of that century in the work of 
philosophically sophisticated writers such as Lambert and Diderot. They disappeared only after Bayesian alternatives were developed by Laplace.

\section{Laplace's Synthesis}

The incorporation of "probability," with its implicit claim of generality, into the mathematical theory of games of chance, creates, of course, a great tension. This tension may have been felt even more strongly in the mid-eighteenth century that it is today.

What do we see in 1750 ? On the one hand, Montmort (who had died prematurely in 1719), Nicolaus (who lived until 1759 but did little in probability after Montmort's death), and De Moivre (who continued to improve the Doctrine of Chances until his death in 1754) had learned how to price expectations in more and more complicated games of chance. Moreover, De Moivre and Simpson had greatly extended the applicability of the theory to the pricing of annuities and insurance. But this was as far as applications went. The theory scarcely lived up to the name "probability." It could not even deal well with the age's most pressing scientific need for quantitative probability judgment: the need to combine astronomical and geodesic observations.

The story of probability in the second half of the eighteenth century has been told well by Steve Stigler and Lorraine Daston. Stigler recounts the practical successes of Mayer, Boscovich, Legendre, and Gauss in combining observations, the early struggle, by Simpson, Bayes, Lambert, Daniel Bernoulli, and Laplace to find methods of combination with a probabilistic rationale, and finally the great successes of Gauss and Laplace in giving probabilistic justifications to the method of least squares. Daston recounts how Laplace, emboldened with this practical success, developed a powerful rhetoric connecting mathematical probability with the very idea of rationality.

In Laplace's rhetoric, the doctrine of chances is the universal tool for measuring our partial knowledge in the face of ignorance. For Laplace as for Jacob, a numerical probability was a degree of certainty: "La probabilité est relative, en partie, à cette 
ignorance, et en partie, à nos connaissances." And it was to be calculated, as Jacob had calculated it, from equally possible cases: "La théorie des probabilités consiste à reduire tous les événemens qui peuvent avoir lieu dans une circonstance donnée, à un certain nombre de cas également possible, e'est-à-dire, tels que nous soyons également indécis sur leur existence."

Laplace's was the first great philosophical mind to come to grips with the mathematical probability after Jacob. Like Jacob, Laplace realized that in order to claim the name "probability" he had to deal with the combination of evidence in general, not just the combination of astronomical observations. And he developed Bayesian rules for the combination of testimony that quickly displaced the non-Bayesian rules (belieffunction or Dempster-Shafer rules, as they are now called) of Jacob, Hooper, and Lambert.

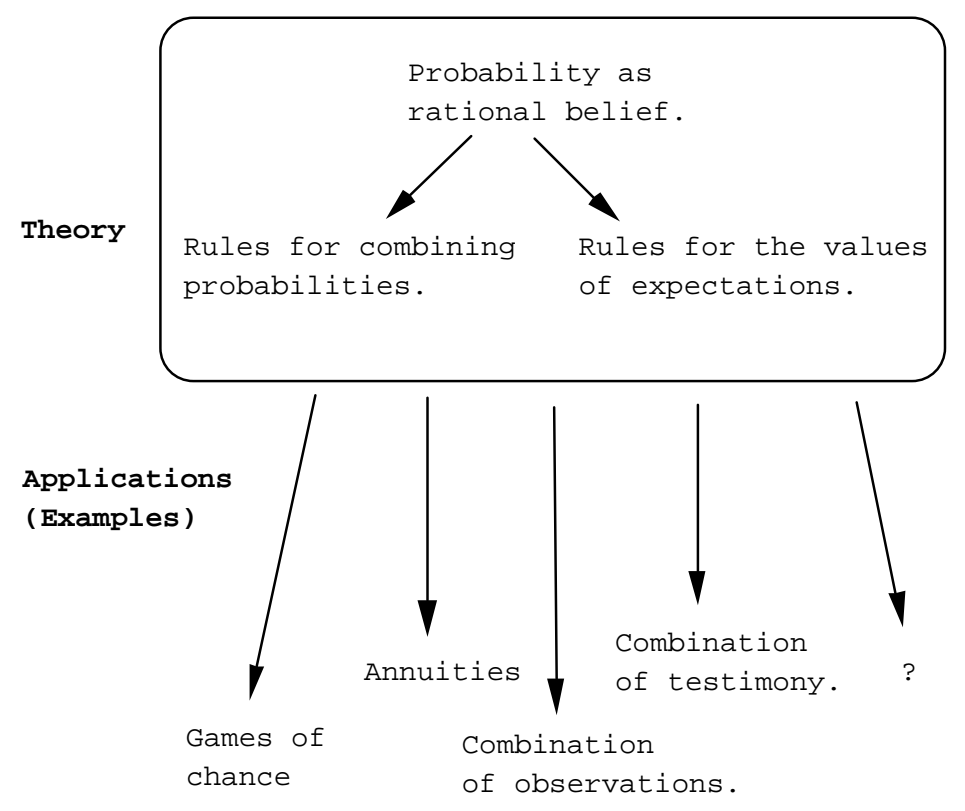

Figure 6 Laplace's picture of probability and its applications.

Figure 6 sketches how Laplace's picture of probability differed from De Moivre's. The most salient difference is the expanded number of applications. But we also see a 
difference within the box marked theory. The rules of probability have now become so familiar that we can pretend they are self-evident. The additivity of probability, for example, no longer needs to be derived from the idea of fair price. Instead, it is taken as axiomatic: a natural and obvious property of rational belief.

My main point here is not the differences between Laplace and De Moivre's pictures, but their commonalities. Figure 6 is more ambitious than Figure 5, but in both cases, the work goes on inside the mathematical theory, and applications are examples of the theoretical structure. In both cases, Jacob's strategy is not needed. If we think through the possibilities, we see the equally possible cases; we do not need to make observations in order to get started. And we do not need to take notice of the different arguments that are made at a pre-quantitative level; everything is supposed to be captured by the equally possible cases.

Daston has spelled out how Laplace's picture was buttressed by an associationist psychology. By virtue of our experience, cases were supposed to present themselves to us with the frequency with which they happened in the world. It would be mistaken, therefore, to draw a sharp opposition between an empiricist Jacob and a rationalist Laplace. There was a good deal of empiricism in Laplace. But the clarity of Jacob's explicit strategy is lost in Laplace. Jacob's explicitness makes clear, above all, the contingency of success of the strategy. We may or may not have enough experience or the right kind of experience to identify equally possible cases. The problem with which we are dealing, and the arguments that we must take into account, may or may not fit Huygens's story. In Laplace, this contingency is replaced by a universal claim of relevance.

\section{The Rise of Frequentism}

I cannot review in detail the decay of Laplace's synthesis and the rise of frequentism in the nineteenth century. The story is well known and recently has been recounted well 
by Ted Porter. Let me simply point out how the frequentist perspective compares with Jacob's strategy.

Jacob's theorem is about frequencies. It says that when the number of trials is large, the relative frequencies with which things happen will approximate the relative ease with which they happen. Were we innocent of history, we might think that the nineteenthcentury philosophers who raised the empiricist banner against Laplace and initiated the tradition now called frequentism might have championed Jacob's theorem, but actually the opposite happened. Richard Leslie Ellis, Jakob Friedrich Fries, and John Venn all saw Jacob's theorem as putting the cart before the horse. They saw Laplace's rational belief and Jacob's ease of happening as equally metaphysical. Frequency alone could serve as the starting point - the definition of probability. We must start by saying that probability is a limit of relative frequencies. And so Jacob's theorem can only be an artificially difficult way of proving something that is right at the surface: a sequence of relative frequencies with a limit will get closer and closer to its limit.

The rejection of Jacob's theorem put the frequentists at odds with the more mathematical probabilists, for even if the theorem was not at the center of the received Laplacean wisdom, it was far too beautiful a piece of mathematics to throw out as nonsense. In time, as the empiricism of the age was internalized by the mathematicians, a more sophisticated frequentism emerged, a frequentism in which the rules of mathematical probability were taken as axiomatic, and the interpretation as frequencies was made vaguer, more holistic, or more dynamic, so that Jacob's theorem could play a role both in interpretation and in the justification of applications.

Notice, however, that this evolution did not bring back Jacob's strategy. The frequentists did not care to define probability as degree of certainty, and they were uninterested in Jacob's rules for combining observations. These rules were an embarrassment, an unusual lapse in the performance of an otherwise admirable intellect. 
One way to explain the difference between Jacob and the frequentists is to say that the frequentists wanted to use the picture of games of chance as an empirical model. Jacob's theorem is one of the predictions that this model makes, and hence one of the ways we can test it. This is not the way Jacob looked at the matter. He saw his theorem as an authorization to use experience to evaluate individual arguments. This is first step. We must then combine arguments.

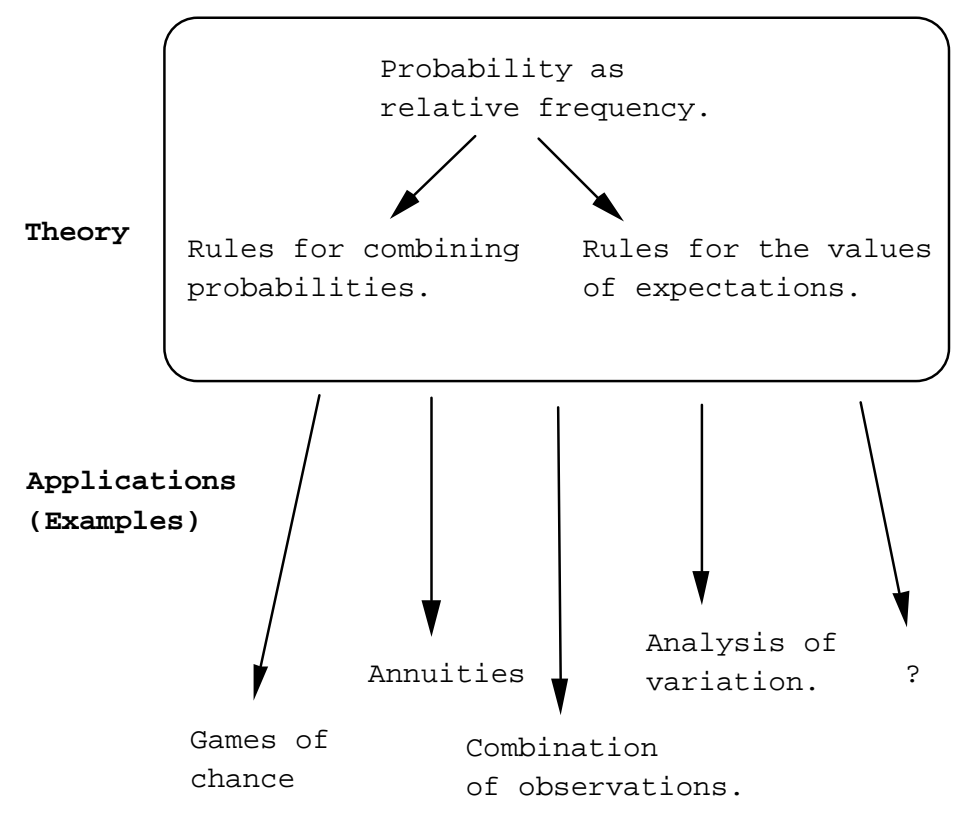

Figure 7 The frequentist picture of probability and its applications.

Another aspect of the difference is that the frequentists preserved De Moivre's original relocation of "probability." As Figure 7 suggests, the frequentist conception of the relation between theory and application is still very similar, in its gross outlines, to the conceptions of De Moivre and Laplace. Laplace's rules for the combination of testimony were loudly rejected, and new applications, which still constitute the material of our introductory statistics courses, were brought to the fore. But the intellectual work remained within the theory; applications were still seen as examples of the theory. 
The frequentists did have in common with Jacob a willingness to fail. In fact, they were far more willing than Jacob to leave vast domains outside their range of application. If there are no relevant limiting frequencies in a problem, it is not, according to the frequentists, a problem for probability. This would have astounded Jacob, who could not have pretended to use the word had he not undertaken to deal with the common run of problems to which it had traditionally been applied.

In recent years I have tried to bring frequentism back closer to Jacob's original vision. My new book, The Art of Causal Conjecture, explores how a unified picture of probability can be used as a model for causal structures in nature, a model in which nature herself is seen as an observer whose ability to predict is indicated by probabilities. This is

frequentist in its emphasis on modeling but Bernoullian in its insistence that probability is concerned with subjective certainty. But while I share with frequentists a fascination with modeling nature, my point here is that Bernoulli saw this as only part of the art of conjecture—only part of "probability."

\section{The Bayesian Revival}

I cannot cite a historian who has told us about the twentieth-century Bayesian revival. It is much closer to our own experience, and we each have our own version of what has happened and where we are. For my own part, I would contend that the Bayesian revival has left unchanged the understanding of the relation between theory and application that we have had since De Moivre and Laplace. 


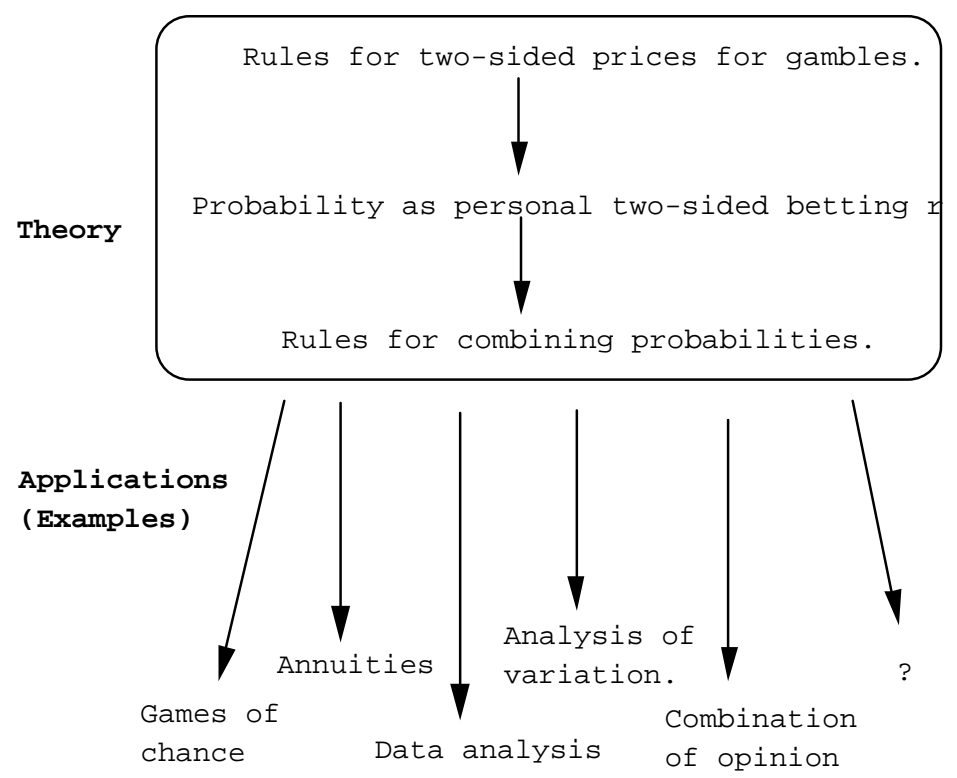

Figure 8 The Bayesian picture of probability and its applications.

As Figure 8 indicates, the Bayesian revival has further broadened the scope of application of probability; it has reclaimed the combination of opinion, rejected by the frequentists. In fact, its aspirations for probability are just as broad as those of Laplace: the claims of universality implicit in the word "probability" are again to be upheld. Itis also clear that the Bayesians have rearranged the furniture within the box marked "Theory." It is this rearrangement that makes the revival "Bayesian" rather "Laplacean": it has taken us back past Laplace to the tradition of Pascal, Huygens, and Bayes, according to which price came first. In contrast to these authors, however, most modern Bayesians have no truck with the metaphysical idea of fairness. Instead, they deal in personal prices - prices at which a particular person is willing to buy and sell gambles.

For my own part, I have never been able to make sense of this purported replacement for the traditional idea of fairness. Why, if a price is not taken to be fair, would a person be willing both to buy and sell at that price? Why, indeed, if we drop as metaphysical (and after the frequentist era too suggestive of a guarantee of long-run equity) the 
assumption that fair prices exist, is it less metaphysical to assume that a personal price (two-sided or for that matter one-sided) exists?

What I want to emphasize, however, is the continuity, from De Moivre to Laplace to the frequentists to the Bayesians, of a general conception of the relation between theory and application. For the Bayesians, as for their predecessors, applications of probability theory are examples. The theory tells shows us the shape of the belief system of an ideal rational person. In order to apply the theory, we must make our beliefs about a particular problem fit that shape.

Is this the most useful picture? Is this really the best and only way to use numerical probability? Does it really make sense to claim that the force of every argument can be captured within a theory of price and reduced to an example of that theory? Or is there something to be gained by looking again at Jacob's conception of application, wherein the many domains of experience and argument were granted their own logical structure and the role of theory was to help us bring these arguments together?

\section{Our Problem Situation}

At the end of Jacob's life, Ars Conjectandi remained unfinished because Jacob had not yet found data that would enable him to construct real examples of the application of the new theory outside games of chance.

Today we have three centuries' worth of real examples. No one disputes that the theory of equity in games of chance, grown into the mathematical theory of probability, has a vast number of applications. But the central philosophical problem of probability is still to understand its limits of application. When is probability applicable and when is it not? How do we explain and regulate its scope? How, indeed, do we criticize applications? How do we judge that it makes sense to use the theory in one case in not in another? 
It is in answering these questions that the frequentist and Bayesian philosophies have failed. The frequentist philosophy sets up an ideal of true randomness so far from the range of most real problems that scarcely any application is strictly meritorious. Indeed, when probabilistic methods are successful, the frequentist tends to be surprised, and rather than explaining such successes, the frequentist philosophy merely leaves us to marvel at the surprising usefulness of false assumptions. The Bayesian philosophy sits at the other extreme, proclaiming all subjective applications legitimate, and giving us no tools at all for criticizing applications or distinguishing between them on the basis of quality.

My prescription for improving this situation is to return to something like Jacob's conception of the relation between theory and application. We should give back to practical problems their own logic, and we should see the task of application as one of bridging, in any of many different ways, the logic of practical problems and the logic of the abstract theory. The theory can indeed sometimes be used as a "model"-frequentist or Bayesian or both, but this is only one of many ways that it can be brought to bear.

The Unified Theory of Probability

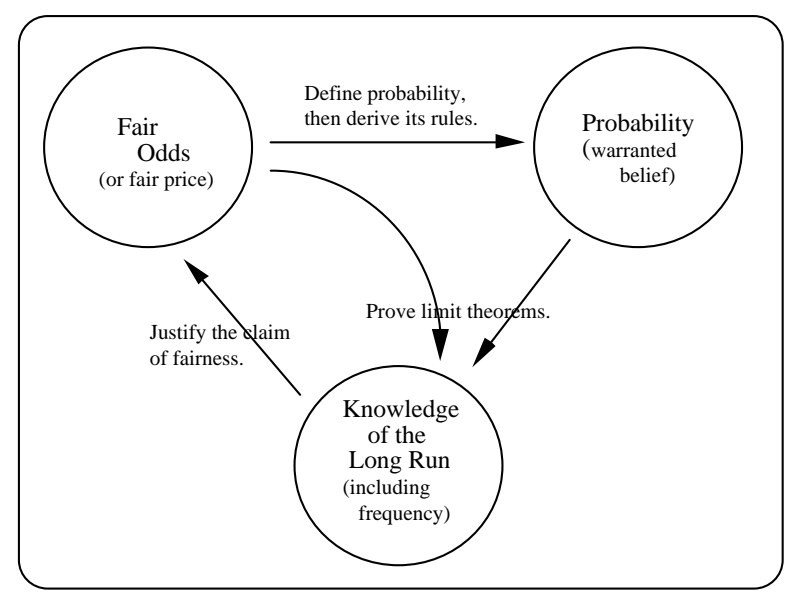

Divers Relations

Prediction in games of chance as a standard of comparison

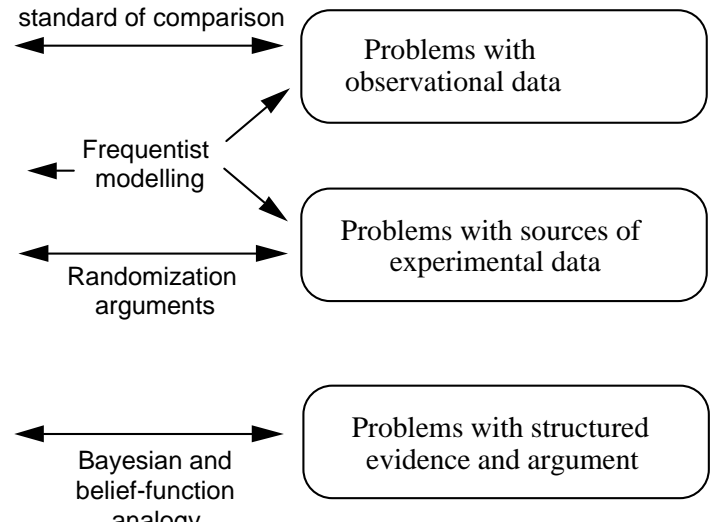

Figure 9 A neo-Jacobean picture of probability and its applications. 
I have laid out my own conception of the relation between theory and application in probability in several recent articles (especially "Can the various meanings of probability be reconciled?"). Figure 9 summarizes it. To begin, I propose that we unify within the theory the elements of truth of the Bayesian and frequentist pictures. The resulting unified picture is not a theory of all the modern applications of probability. On the contrary, it is once again merely a theory of games of chance. But it brings together all that we have learned about such games since Huygens: the gambler has long-run knowledge as well as knowledge of immediate fair prices, and the structure of the game is at once the protocol for how events can happen and the protocol governing how the gambler's knowledge can grow. And this unified picture can be related to practical problems in divers ways. Statistical tests, though usually packaged as frequentist models, often only make sense if they are taken as using the unified picture as a standard to which to compare the performance of a predictor. Randomization arguments typically involve the construction of an instance of the unified picture, which is deliberately intertwined with a causal structure we want to understand. And both Bayesian and belief-function arguments can be understood as imitations of and analogies to the structure of practical arguments.

As I suggested in my introduction, the time may be ripe for the acceptance of a picture like Figure 9. Why this optimism? Why do I think that the century-old frequentistBayesian standoff may be nearing an end? First it has become tiresome, and secondly because the simple-minded empiricism on which both the frequentist and the Bayesian pictures are founded is out of fashion. It is no longer exciting to talk about modelingwhether we be modeling nature or belief. We are interested in recognizing more subtle relations between the story of a theory and the reality it is supposed to create or understand.

Moreover, new applications of probability are stretching the received understandings and making increasingly awkward the inability of these understandings to deal with the 
quality of application. I am thinking especially of applications in economics and expert systems. In both cases, there is often a confrontation between probabilistic and nonprobabilistic methods that cries out for non-dogmatic adjudication. And in both cases we see emerging a new understanding of the evaluation of probability forecasting (I refer here to the work of Dawid and Vovk and to my own Art of Causal Conjecture) that again unites belief and frequency and calls for a subtler understanding of application.

Finally, there is another expectation that encourages me to hope that the posthumous influence of Jacob Bernoulli may soon revive to rival that of Pierre Simon and Thomas Bayes. This is the prospect that Edith Sylla, Anthony Edwards, and I will soon complete our long-delayed English translation, with commentary, of Ars Conjectandi. I hope that we shall be able soon to speak of the Art of Conjecture.

\section{Acknowledgments}

This article has benefited from discussions with Fritz Nagel, Stephen M. Stigler, and Edith Sylla, as well as from suggestions by referees. Partial support for the research was provided by grant SBE9213674 from the National Science Foundation.

\section{References}

Arnauld, Antoine, and Pierre Nicole (1662). l'Art de penser. Paris. Widely used as a textbook, with many editions and translations, this book is often referred to as the Port Royal Logic.

Daston, Lorraine (1988). Classical Probability in the Enlightenment. Princeton University Press, Princeton, New Jersey.

Dawid, A.P. (1984). Statistical theory: The prequential approach. Journal of the Royal Statistical Society, Series A 147 278-292.

Edwards, A.W.F. (1987). Pascal's Arithmetic Triangle. Oxford University Press, New York. 
Hacking, Ian (1975). The Emergence of Probability. Cambridge University Press, Cambridge, England.

Hald, Anders (1990). A History of Probability and Statistics and their Applications before 1750. Wiley, New York.

Porter, Theodore M. (1986). The Rise of Statistical Thinking, 1820-1900. Princeton University Press. Princeton, New Jersey.

Shafer, Glenn (1978). Non-additive probabilities in the work of Bernoulli and Lambert. Archive for History of Exact Sciences 19 309-370.

Shafer, Glenn (1990). Perspectives on the theory and practice of belief functions. International Journal of Approximate Reasoning 4 323-362.

Shafer, Glenn (1992). Can the various meanings of probability be reconciled? Pp. 165196 of A Handbook for Data Analysis in the Behavioral Sciences: Methodological Issues, ed. G. Keren and C. Lewis, Hillsdale, N.J.: Lawrence Erlbaum.

Shafer, Glenn (1996). The Art of Causal Conjecture. Cambridge, MA: The MIT Press. Shapiro, Barbara J. 1983. Probability and Certainty in Seventeenth-Century England: A Study of the Relationships between Natural Science, Religion, History, Law, and Literature. Princeton University Press.

Stigler, Stephen M. (1986). The History of Statistics: The Measurement of Uncertainty before 1900. Harvard University Press. Cambridge, Massachusetts.

van der Waerden, B.L. (1975) Die Werke von Jakob Bernoulli, Band 3. Herausgegeben von der Naturforschenden Gesellschaft in Basel. Birkhäuser Verlag. Basel.

Vovk, V.G. (1993). The logic of probability. Journal of the Royal Statistical Society, Series B, 55 317-351.

Zabell, Sandy L. (1988). The probabilistic analysis of testimony. Journal of Planning and Inference $20327-354$. 